\title{
Modern Cerebrospinal Fluid Flow Research and Heinrich Quincke's Seminal 1872 Paper on the Distribution of Cinnabar in Freely Moving Animals
}

\author{
Helene Benveniste ${ }^{1,}$, Patrick R. Hof ${ }^{2}$, Maiken Nedergaard ${ }^{3}$, and Karl Bechter ${ }^{4}$ \\ ${ }^{1}$ Departments of Anesthesiology and Radiology, University of Stony Brook, School of Medicine, \\ Stony Brook NY 11794, USA \\ ${ }^{2}$ Fishberg Department of Neuroscience and Friedman Brain Institute, Icahn School of Medicine at \\ Mount Sinai, New York, NY 10029, USA \\ ${ }^{3}$ Center for Translational Neuromedicine, University of Rochester Medical Center, School of \\ Medicine, Rochester, NY 14642, USA \\ ${ }^{4}$ Department of Psychosomatics/Psychotherapy, Ulm University, D-89312 Günzburg, Germany
}

\begin{abstract}
The discovery of the 'glymphatic' pathway has shed new light on the cerebrospinal (CSF)brain interstitial fluid (ISF) exchange process (Iliff et al., 2012). In new anatomically defined terms, the glymphatic pathway now represents a brain-wide pathway where CSF flows through the brain and spinal cord parenchyma and exchanges with ISF from periarterial to perivenous spaces in a route interconnected by aquaporin 4 water channels present on glial cells (Iliff et al., 2012). The new concept of the glymphatic pathway has evolved from the older concept of bulk flow of ISF from brain parenchyma to the ventricular CSF referred to as the "ependymal pathway" (Brightman, 1965a,b). The glymphatic pathway is important for detoxification of the brain (and spinal cord), a cleaning process that appears to be driven by adrenergic tone (Xie et al., 2013), arterial pulsatility (Iliff et al., 2013b), level of arousal (Xie et al., 2013), and aging (Kress et al., 2014). For decades, brain pulsations have been observed directly during neurosurgical procedures. Pulsation of the CSF was first qualitatively described in vivo using fluoroscopy (Du Boulay, 1966) and then validated using non-invasively using magnetic resonance imaging (MRI) (Sherman and Citrin, 1986; Sherman et al., 1986). A comprehensive review of this topic by Wagshul and coworkers was recently published (Wagshul et al., 2011). Phase-contrast MRI was later used to quantify CSF pulsation in selected parts of the ventricular CSF spaces, followed by quantitative flow visualization in the entire subarachnoid and ventricular spaces through computational flow reconstruction from phase-contrast MRI data (Gupta et al., 2010; Cheng et al., 2012; Siyahhan et al., 2014). Major aspects of CSF flow dynamics and outflow
\end{abstract}

"CORRESPONDENCE TO: Helene Benveniste, MD, PhD, Department of Anesthesiology, Stony Brook Medicine, Stony Brook, NY 11794, Helene.benveniste@ stonybrookmedicine.edu.

CONFLICT OF INTEREST

The authors declare no conflicts of interest.

ROLE OF AUTHORS

All authors contributed equally to the elaboration of this commentary. 
pathways are now more fully characterized (Wagshul et al., 2006; Oreskovic and Klarica, 2010; Bulat and Klarica, 2011). All of these experimental and mathematical modeling studies have led the conclusion that for example 'pressure pulsatility' in the brain functions as an internal biosensor of intracranial compliance (Wagshul et al., 2011) which is heightened in chronic hydrocephalus (Greitz, 2004). CSF reabsorption via the arachnoid villi into the dural sinuses to the blood or through the nasal lymphatics have been previously documented in seminal papers (Boulton et al., 1996; Abbott, 2004; Johnston et al., 2004). Nevertheless, important questions pertaining to CSF drainage remain unanswered. For example, the exact anatomy of the subarachnoid spaces along cranial and spinal nerves, the functional (quantitative and directional) relationship between influx of CSF into the brain and lymphatic drainage of CSF-ISF, and the potentially fluctuating outflow volumes at the various exit points along the complex outflow pathways, which under normal conditions may be dependent on posture, activity and state of consciousness. The influence of body posture and respiration on CSF outflow and transport has been characterized; and continues to be investigated using MRI techniques with improved temporal resolution (Bradbury et al., 1981; Bradbury and Westrop, 1983; Alperin et al., 2005; Yamada et al., 2013). However, another exceedingly important area that is only partially understood is how physiological movement and various motor activities affects CSF movements and outflow patterns. This lack of information is paradoxical because the influence of motor activity is clearly playing a prominent role on CSF-ISF exchange and clearance (Bechter, 2011). For example, local muscle tone change associated with yawning changes CSF dynamics (Walusinski, 2014). To our knowledge, one of the best studies on CSF flow and outflow pathways have been performed by Heinrich Quincke and described in a paper he published in "Archiv für Anatomie, Physiologie und wissenschaftliche Medicin" in 1872 (Quincke, 1872). In his studies, Quincke experimented with freely moving animals, injecting the particulate dye cinnabar (Mercury(II) sulfide, $\mathrm{HgS}$ ) into the intrathecal spaces of dogs, cats, and rabbits, all animals with high motor activity, and analyzed the dye's distribution throughout the body after days, weeks or months postmortem.

It is well established that the CSF not only represents a means for removing waste products from the brain and spinal cord but also serves a role as an important medium for signaling, which is mediated by free molecules (such as neuropeptides, neurotransmitters), exosomes and microparticles, and not the least, cells (Rodriguez, 1976). In addition, proteomics studies have also shed light on the functional role of CSF and revealed a wide range of biomarkers including proteins involved in $\mathrm{A} \beta$ transport and proteolytic inhibition, as well as extracellular matrix factors important for neuronal migration (Zappaterra et al., 2007; Roche et al., 2008). The CSF is also in constant exchange with the ISF of the central nervous system (CNS), summarized well in the so-called "volume transmission hypothesis" (Fuxe et al., 1989; Agnati et al., 2006; Fuxe et al., 2007) and as such may constitute a 'wireless' circuitry influencing cognitive and behavioral processes. Thus, the pathways of CSF flow and signaling are of interest to understand CNS functions in general better. Interestingly, in recent years, the outflow pathways of CSF were mainly studied at the level of the cribriform plate (Johnston and Papaiconomou, 2002; Johnston et al., 2004) and only lately CSF cell trafficking has also proven to take place via this process (Bechmann et al., 2001), which was also established to occur along lumbar nerves (Schmitt et al., 2011). The cells in CSF seem 
to have important yet poorly understood functions in physiological and pathological situations: immune cells recruited from the blood into the CSF spaces directly support CNS functions (Baruch and Schwartz, 2013). It is therefore not surprising, that the CSF itself and CSF pathways are gaining an increasing general research interest in many clinical disciplines.

In the so-called "peripheral CSF outflow pathway" (PCOP) hypothesis (Bechter, 2011) a possible role of CSF signaling was proposed even at sites downstream from the subarachnoid space along cranial and peripheral nerves. Given that CSF signaling extends physiologically so far away from the CNS, research in this area is likely to have an unprecedented importance for better understanding the pathogenesis in neuroinflammatory disorders of the peripheral nervous system, including polyneuropathy, and for pain research in general (Bechter, 2011; Maxeiner et al., 2014). Therefore, the physiological patterns and variances of CSF flow and outflow would be important to characterize in more detail. Also these CSF outflow patterns appear to be of interest for oncology, as tumor cells (as well as chemotherapeutic agents) can apparently follow the PCOP (Schmitt et al., 2011). For example, so-called chloromas along peripheral nerves were more frequently observed since the introduction of effective antitumor treatments with antibodies, which however seem less effective within the intrathecal spaces (Sandhu et al., 1998; Colella et al., 2005; Thakar et al., 2012).

We attempted to translate the original Quincke's paper by remaining as faithful to the original text, which is written in an old-fashioned form of scientific German, and nowadays appears constructed and at times difficult to interpret. Quincke's studies were clearly serious research (Bechter et al., 2015), and we should not forget his contribution (Quincke, 1891) to the procedure of lumbar puncture that revolutionized medicine and anesthesiology (an area of medicine not yet developed into a separate discipline in 1872).

The historical studies by Quincke are unique and a translation into English is therefore not only timely but will be of great interest to many researchers in the growing field of CSF physiology and CSF flow dynamics. Quincke's studies appear to be performed in a very systematic and judicious manner and he described his experiments in minute detail although his paper is published without accompanying drawings. What Quincke observed in his experiments is of interest beyond a simple historical perspective, because observations in freely moving animals surviving weeks after injection of particulate dye into the intrathecal spaces were implemented in his experimental design, providing invaluable insights in understanding the CSF outflow pathways. Most importantly, Quincke took care to preserve as much as possible the normal physiological conditions during dye injection of into the CSF. For instance, he used a tiny needle to inject the dye into the lumbar subarachnoid space and did not remove bone therefore preserving the pressure conditions within the vertebral column; for the subarachnoid injections at the level of the skull he used a small diameter trocar and immediately sealed the opening with a 'wooden pin' again being careful not to disturb the intracranial pressure gradients and/or cause continued CSF leakage; and the injected volume of dye was relatively small so that it did not overpressurize the CSF spaces, which would have resulted in reflux of dye material into the ventricles or into the spinal canal. Quincke was clearly aware that his own manipulations could alter the movement of 
CSF: small CSF leaks can reduce pressure and thereby CSF flux, whereas injection of large volume of fluid in the subarachnoid space potentially creates non-physiological patterns of CSF flow. The same concerns still apply to studies of CSF fluxes today.

The major findings of Quincke's studies can be summarized as follows:

- A subdural space only exists in the brain (described as a 'capillary fluid layer', Fig. 1A), whereas in the spinal cord such a space is not present (Fig. 1B). If the dye is injected into the subdural space, the CSF currents flow preferentially towards the subarachnoid space and the dye will quickly disappear from the subdural space.

- The subarachnoid dye injection studies show that fluid in the subarachnoid spaces of the brain and the spinal cord communicates.

- The distribution pattern of dye when injected into the lumbar subarachnoid space and/or the brain subarachnoid space is largely the same. However, more dye is transported to the brain when it is injected in to the lumbar subarachnoid space, and vice versa.

- Outflow pathways of CSF tagged with cinnabar (Fig. 2):

- $\quad$ Along intercostal nerves

- $\quad$ Along lumbar and sacral nerves - as far as to the lumbar and sacral plexi

- Olfactory nerve (however not beyond the cribriform plate)

- Always along the optic nerve (a consistent finding)

- Pacchioni's granulations at the superior sagittal sinus and transverse sinus

- Along trigeminal nerve but not beyond the exit points from the skull

- $\quad$ Carotid sheet

- $\quad$ Large cervical and submaxillary lymphatic glands

- Within lymphocytes and rounded cells (macrophages?) along nerve trunks

- $\quad$ Along the azygos vein

- In lymph nodes along the aorta

- Locations at which cinnabar was not (or rarely) observed:

- Within the brain parenchyma or within the nerve trunks

- Never in the trigeminal ganglion or in the spinal ganglia

- Never in the spleen or the nasal mucosa

- Rarely found in the ventricles; and if so mostly in the epithelium

- Never in the retina 
- The wide distribution of dye within the subarachnoid space of spinal cord and brain is considered to be caused by respiratory movement and pressure propagated from the arteries.

- In a few experiments, he injected dye into the ventricles and found that they are connected to subarachnoid spaces but these connections are not clearly defined.

The information from Quincke's seminal paper has in some aspects to be considered with caution, as some assumptions are now disproved; for example, CSF production in the choroid plexus had not yet been discovered when he wrote his paper. However, such lack of proper physiological and anatomical knowledge is not surprising given that these studies represent the first ones on the subject. Furthermore, considering the seminal work by Johnston and colleagues demonstrating that CSF absorption into nasal lymphatics is observed in all mammals including humans (Johnston et al., 2004), it is noteworthy that Quincke did not observe cinnabar in the nasal mucosa, which might be related to the size of the cinnabar granules that he used (see below for more details on this topic). The paper was written about 20 years before Quincke introduced lumbar puncture into medicine (Cozanitis, 2013). Important open questions in psychiatry and neurology were solved with this new method of CSF access. For example, availability of CSF for diagnostics contributed to end debates about the causes of general paralysis, which were solved with the advent of lumbar puncture and antibody detection (Wassermann reaction; Bechter et al., 1995; Cozanitis, 2013). We believe that Quincke's studies were the first to reveal fundamental concepts about the pathogenesis of neuropsychiatric disorders, and especially of neuroinflammatory states.

Recent in vivo analysis of the glymphatic system show that CSF flows in the perivascular space and is rapidly pumped along penetrating arteries in rodents (Iliff et al., 2012; Iliff et al., 2013a; Nedergaard, 2013; Iliff et al., 2014), while earlier work have documented the existence of the same influx path in larger animals such as dogs and cats (Rennels et al., 1985; Rennels et al., 1990). The perivascular space is interposed between the endothelial cells and the perivascular astrocytic end-feet; and this compartment surrounds the entire vasculature in CNS. Arterial pulsations drive CSF from the perivascular space into the brain parenchyma where it mixes with the ISF. The excess CSF-ISF mix collects around the deep penetrating veins (and in the olfactory bulb) from where it drains out along vasculature into lymphatic vessels that empty out into the general circulation. Given what we now know about CSF flow, penetrating arteries and CSF-ISF exchange, why, then, did Quincke not observe influx of cinnabar into the brain or spinal cord in his experiments? To address this question, we conducted a few experiments with cinnabar injections into the cisterna magna of mice. The analysis showed that a $10 \%$ aqueous solution of cinnabar $(10 \mathrm{Ql}$, injected over 5 min with $30 \mathrm{~min}$ circulation prior to perfusion-fixation) was needed to visualize cinnabar by brightfield microscopy (Fig. 3A). These experiments were conducted in 7 adult male mice. The animals were deeply anesthetized with a mixture of ketamine $(80-100 \mathrm{mg} / \mathrm{kg}$ ) and xylazine $(5-10 \mathrm{mg} / \mathrm{kg})$ ip and perfusion-fixed at the end of the experiments. All experiments were conducted at the University of Rochester Medical Center, and adhered to the NIH guidelines for care and use of laboratory animals, and were approved by the relevant institutional ethical committee. Cinnabar was only found in the cisterna magna when 
artificial cerebrospinal fluid (aCSF) containing 2-10\% cinnabar was injected. Inspection of brain and spinal cord revealed small aggregates of cinnabar sticking to the pia at interfaces between brain and cerebellum or pons, and particularly around the large basal vessels (Fig. 3A). Cinnabar crystals were also observed on the surface of the spinal cord (Fig. 3B). Preparation of vibratome sections showed that cinnabar never entered the perivascular spaces and remained at the surface of the brain. In contrast, ovalbumin-tagged with Texas Red (MW $42.7 \mathrm{kDa}, 1 \%$ solution, in $10 \mu \mathrm{l}$ aCSF injected over 5 min with 30 min circulation prior to perfusion-fixation) entered the brain along the largest penetrating vessels as well as along the pial surface (Fig. 3C). Microscopic imaging of cinnabar revealed that it remained as large red crystals ( $>20 \mu \mathrm{m}$-wide) even after extensive vortexing to get it into solution. It is therefore not surprising that cinnabar did not enter brain or spinal cord along the glymphatic pathway as it is too large and remains in CSF around the brain and spinal cord. This explains why Quincke (1872) did not observe cinnabar within the brain parenchyma itself. It remains that Quincke's pioneering experiments uncovered the physiology of CSF and provided seminal observations that today find their application in many domains of neurology and psychiatry.

\section{ACKNOWLEDGEMENTS}

We thank Drs. Emi Hitomi and Rashid Deane for their expert help with the cinnabar injection experiments, and Ms. Kathleen Gebhart for her help with the illustrations.

Grant sponsor: NIH; Grant Numbers: AG005138 (PRH) and AG048769 (HB, MN); Grant sponsor: Department of Anesthesiology, Stony Brook Medicine, and an anonymous gift (HB); Grant sponsor: Margarete-Ammon-Stiftung, Münich (KB)

\section{LITERATURE CITED}

Abbott NJ. Evidence for bulk flow of brain interstitial fluid: significance for physiology and pathology. Neurochem Int. 2004; 45:545-552. [PubMed: 15186921]

Agnati LF, Leo G, Zanardi A, Genedani S, Rivera A, Fuxe K, Guidolin D. Volume transmission and wiring transmission from cellular to molecular networks: history and perspectives. Acta Physiol. 2006; 187:329-344.

Alperin N, Hushek SG, Lee SH, Sivaramakrishnan A, Lichtor T. MRI study of cerebral blood flow and CSF flow dynamics in an upright posture: the effect of posture on the intracranial compliance and pressure. Acta Neurochir Suppl. 2005; 95:177-181. [PubMed: 16463846]

Baruch K, Schwartz M. CNS-specific T cells shape brain function via the choroid plexus. Brain Behav Immun. 2013; 34:11-16. [PubMed: 23597431]

Bechmann I, Priller J, Kovac A, Bontert M, Wehner T, Klett FF, Bohsung J, Stuschke M, Dirnagl U, Nitsch R. Immune surveillance of mouse brain perivascular spaces by blood-borne macrophages. Eur J Neurosci. 2001; 14:1651-1658. [PubMed: 11860459]

Bechter K. The peripheral cerebrospinal fluid outflow pathway - physiology and pathophysiology of CSF recirculation: a review and hypothesis. Neurol Psychiatry Brain Res. 2011; 17:51-66.

Bechter K, Herzog S, Behr W, Schuttler R. Investigations of cerebrospinal fluid in Borna disease virus seropositive psychiatric patients. Eur Psychiatry. 1995; 10:250-258. [PubMed: 19698348]

Bechter K, Hof PR, Benveniste H. On the flow dynamics of cerebrospinal fluid [A translation of Quincke's 1872 paper "Zur Physiologie der Cerebrospinalfluessigkeit" in Arch Anat Physiol Wiss Med 1872;153-177]. Neurol Psychiatry Brain Res. 2015 (in press).

Boulton M, Young A, Hay J, Armstrong D, Flessner M, Schwartz M, Johnston M. Drainage of CSF through lymphatic pathways and arachnoid villi in sheep: measurement of 125I-albumin clearance. Neuropathol Appl Neurobiol. 1996; 22:325-333. [PubMed: 8875467] 
Bradbury MW, Cserr HF, Westrop RJ. Drainage of cerebral interstitial fluid into deep cervical lymph of the rabbit. Am J Physiol. 1981; 240:F329-F336. [PubMed: 7223890]

Bradbury MW, Westrop RJ. Factors influencing exit of substances from cerebrospinal fluid into deep cervical lymph of the rabbit. J Physiol. 1983; 339:519-534. [PubMed: 6411905]

Brightman MW. The distribution within the brain of ferritin injected into cerebrospinal fluid compartments. I. Ependymal distribution. J Cell Biol. 1965a; 26:99-123. [PubMed: 5859025]

Brightman MW. The distribution within the brain of ferritin injected into cerebrospinal fluid compartments. II. Parenchymal distribution. Am J Anat. 1965b; 117:193-219. [PubMed: 5883189]

Bulat M, Klarica M. Recent insights into a new hydrodynamics of the cerebrospinal fluid. Brain Res Rev. 2011; 65:99-112. [PubMed: 20817024]

Cheng S, Stoodley MA, Wong J, Hemley S, Fletcher DF, Bilston LE. The presence of arachnoiditis affects the characteristics of CSF flow in the spinal subarachnoid space: a modelling study. $\mathrm{J}$ Biomech. 2012; 45:1186-1191. [PubMed: 22386041]

Colella G, Tirelli A, Capone R, Rubini C, Guastafierro S. Myeloid sarcoma occurring in the maxillary gingiva: a case without leukemic manifestations. Int J Hematol. 2005; 81:138-141. [PubMed: 15765782]

Cozanitis DA. Heinrich Irenaeus Quincke (1842-1922): the Nobel Prize but for the problem of age. Presse Med. 2013; 42:464-470. [PubMed: 23260761]

Du Boulay GH. Pulsatile movements in the CSF pathways. Br J Radiol. 1966; 39:255-262. [PubMed: 5295581]

Fuxe K, Agnati LF, Zoli M, Bjelke B, Zini I. Some aspects of the communicational and computational organization of the brain. Acta Physiol Scand. 1989; 135:203-216. [PubMed: 2564717]

Fuxe K, Dahlström A, Høistad M, Marcellino D, Jansson A, Rivera A, Diaz-Cabiale Z, Jacobsen K, Tinner-Staines B, Hagman B, Leo G, Staines W, Guidolin D, Kehr J, Genedani S, Belluardo N, Agnati LF. From the Golgi-Cajal mapping to the transmitter-based characterization of the neuronal networks leading to two modes of brain communication: wiring and volume transmission. Brain Res Rev. 2007; 55:17-54. [PubMed: 17433836]

Greitz D. Radiological assessment of hydrocephalus: new theories and implications for therapy. Neurosurg Rev. 2004; 27:145-165. [PubMed: 15164255]

Gupta S, Soellinger M, Grzybowski DM, Boesiger P, Biddiscombe J, Poulikakos D, Kurtcuoglu V. Cerebrospinal fluid dynamics in the human cranial subarachnoid space: an overlooked mediator of cerebral disease. I. Computational model. J Roy Soc Interface. 2010; 7:1195-1204. [PubMed: 20236960]

Iliff JJ, Chen MJ, Plog BA, Zeppenfeld DM, Soltero M, Yang L, Singh I, Deane R, Nedergaard M. Impairment of glymphatic pathway function promotes tau pathology after traumatic brain injury. $\mathrm{J}$ Neurosci. 2014; 34:16180-16193. [PubMed: 25471560]

Iliff JJ, Lee H, Yu M, Feng T, Logan J, Nedergaard M, Benveniste H. Brain-wide pathway for waste clearance captured by contrast-enhanced MRI. J Clin Invest. 2013a; 123:1299-1309. [PubMed: 23434588]

Iliff JJ, Wang M, Liao Y, Plogg BA, Peng W, Gundersen GA, Benveniste H, Vates GE, Deane R, Goldman SA, Nagelhus EA, Nedergaard M. A paravascular pathway facilitates CSF flow through the brain parenchyma and the clearance of interstitial solutes, including amyloid beta. Science Translat Med. 2012; 4:147ra111.

Iliff JJ, Wang M, Zeppenfeld DM, Venkataraman A, Plog BA, Liao Y, Deane R, Nedergaard M. Cerebral arterial pulsation drives paravascular CSF-interstitial fluid exchange in the murine brain. J Neurosci. 2013b; 33:18190-18199. [PubMed: 24227727]

Johnston M, Papaiconomou C. Cerebrospinal fluid transport: a lymphatic perspective. News Physiol Sci. 2002; 17:227-230. [PubMed: 12433975]

Johnston M, Zakharov A, Papaiconomou C, Salmasi G, Armstrong D. Evidence of connections between cerebrospinal fluid and nasal lymphatic vessels in humans, nonhuman primates and other mammalian species. Cerebrospinal Fluid Res. 2004; 1:2. [PubMed: 15679948]

Kress BT, Iliff JJ, Xia M, Wang M, Wei HS, Zeppenfeld D, Xie L, Kang H, Xu Q, Liew JA, Plog BA, Ding F, Deane R, Nedergaard M. Impairment of paravascular clearance pathways in the aging brain. Ann Neurol. 2014; 76:845-861. [PubMed: 25204284] 
Maxeiner HG, Marion Schneider E, Kurfiss ST, Brettschneider J, Tumani H, Bechter K. Cerebrospinal fluid and serum cytokine profiling to detect immune control of infectious and inflammatory neurological and psychiatric diseases. Cytokine. 2014; 69:62-67. [PubMed: 25022963]

Nedergaard M. Garbage truck of the brain. Science. 2013; 340:1529-1530. [PubMed: 23812703]

Oreskovic D, Klarica M. The formation of cerebrospinal fluid: nearly a hundred years of interpretations and misinterpretations. Brain Res Rev. 2010; 64:241-262. [PubMed: 20435061]

Quincke H. Zur Physiologie der Cerebrospinalfluessigkeit. Arch Anat Physiol Wiss Med. 1872:153177.

Quincke H. Die Lumbalpunktion des Hydrocephalus. Berl Klin Wschr. 1891; 38:929-933.

Rennels ML, Blaumanis OR, Grady PA. Rapid solute transport throughout the brain via paravascular fluid pathways. Adv Neurol. 1990; 52:431-439. [PubMed: 2396537]

Rennels ML, Gregory TF, Blaumanis OR, Fujimoto K, Grady PA. Evidence for a 'paravascular' fluid circulation in the mammalian central nervous system, provided by the rapid distribution of tracer protein throughout the brain from the subarachnoid space. Brain Res. 1985; 326:47-63. [PubMed: 3971148]

Roche S, Gabelle A, Lehmann S. Clinical proteomics of the cerebrospinal fluid: towards the discovery of new biomarkers. Proteomics Clin Applic. 2008; 2:428-436.

Rodriguez EM. The cerebrospinal fluid as a pathway in neuroendocrine integration. J Endocrinol. 1976; 71:407-443. [PubMed: 794431]

Sandhu GS, Ghufoor K, Gonzalez-Garcia J, Elexpuru-Camiruaga JA. Granulocytic sarcoma presenting as cauda equina syndrome. Clin Neurol Neurosurg. 1998; 100:205-208. [PubMed: 9822843]

Schmitt M, Neubauer A, Greiner J, Xu X, Barth TF, Bechter K. Spreading of acute myeloid leukemia cells by trafficking along the peripheral outflow pathway of cerebrospinal fluid. Anticancer Res. 2011; 31:2343-2345. [PubMed: 21737662]

Sherman JL, Citrin CM. Magnetic resonance demonstration of normal CSF flow. Am J Neuroradiol. 1986; 7:3-6. [PubMed: 3082142]

Sherman JL, Citrin CM, Gangarosa RE, Bowen BJ. The MR appearance of CSF pulsations in the spinal canal. Am J Neuroradiol. 1986; 7:879-884. [PubMed: 3096108]

Siyahhan B, Knobloch V, de Zelicourt D, Asgari M, Schmid Daners M, Poulikakos D, Kurtcuoglu V. Flow induced by ependymal cilia dominates near-wall cerebrospinal fluid dynamics in the lateral ventricles. J Roy Soc Interface. 2014; 11:20131189. [PubMed: 24621815]

Thakar S, Dadlani R, Ghosal N, Jethwani D, Mahadevan A, Hegde AS. Multiple intracranial de-novo chloromas presenting with Garcin's syndrome. Clin Neuropathol. 2012; 31:369-373. [PubMed: 22541780]

Wagshul ME, Chen JJ, Egnor MR, McCormack EJ, Roche PE. Amplitude and phase of cerebrospinal fluid pulsations: experimental studies and review of the literature. J Neurosurg. 2006; 104:810819. [PubMed: 16703889]

Wagshul ME, Eide PK, Madsen JR. The pulsating brain: A review of experimental and clinical studies of intracranial pulsatility. Fluids Barriers CNS. 2011; 8:5. [PubMed: 21349153]

Walusinski O. How yawning switches the default-mode network to the attentional network by activating the cerebrospinal fluid flow. Clin Anat. 2014; 27:201-209. [PubMed: 23813685]

Xie L, Kang H, Xu Q, Chen MJ, Liao Y, Thiyagarajan M, O'Donnell J, Christensen DJ, Nicholson C, Iliff JJ, Takano T, Deane R, Nedergaard M. Sleep drives metabolite clearance from the adult brain. Science. 2013; 342:373-377. [PubMed: 24136970]

Yamada S, Miyazaki M, Yamashita Y, Ouyang C, Yui M, Nakahashi M, Shimizu S, Aoki I, Morohoshi Y, McComb JG. Influence of respiration on cerebrospinal fluid movement using magnetic resonance spin labeling. Fluids Barriers CNS. 2013; 10:36. [PubMed: 24373186]

Zappaterra MD, Lisgo SN, Lindsay S, Gygi SP, Walsh CA, Ballif BA. A comparative proteomic analysis of human and rat embryonic cerebrospinal fluid. J Proteome Res. 2007; 6:3537-3548. [PubMed: 17696520] 


\section{A - Skull}

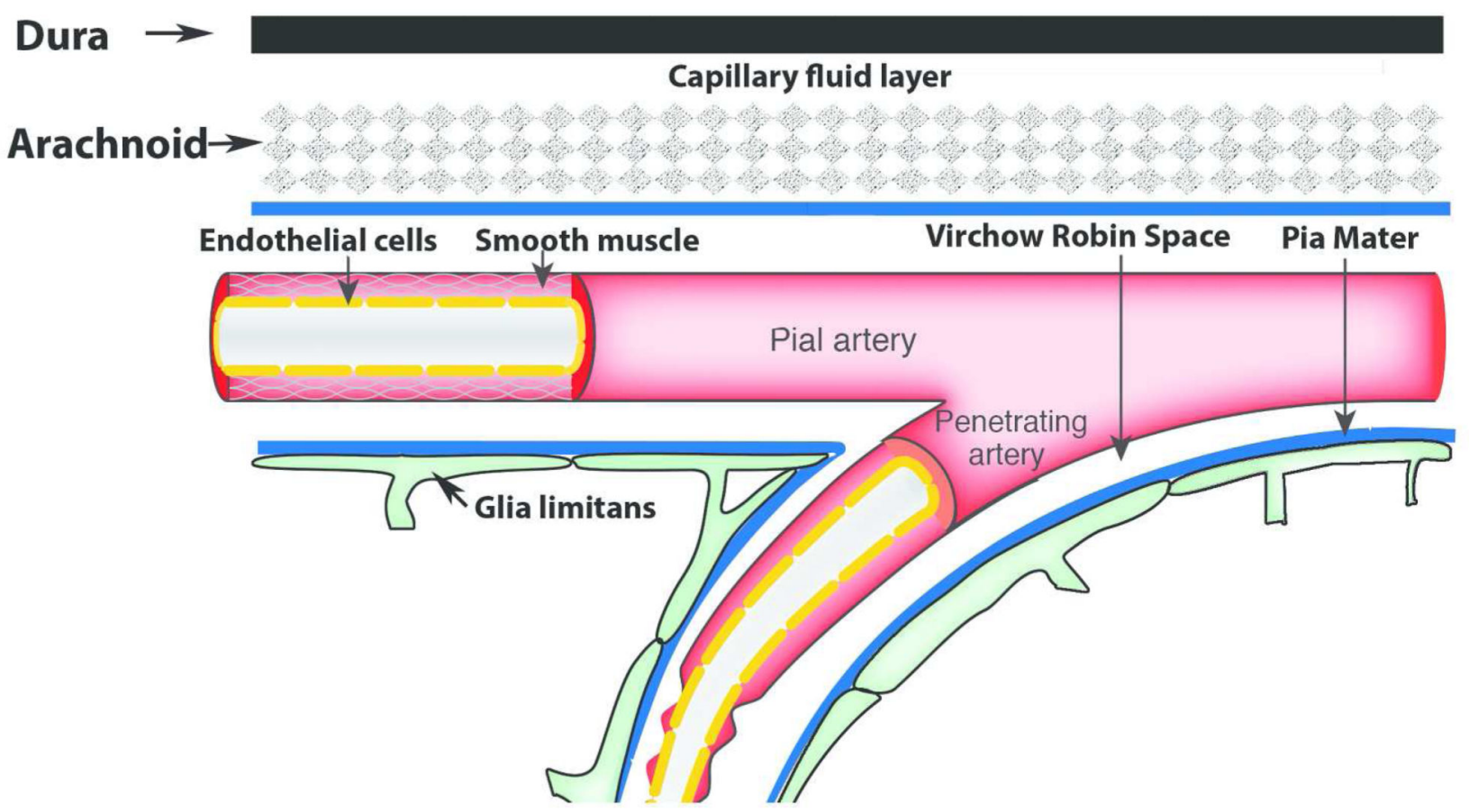

\section{B- Spinal Cord}

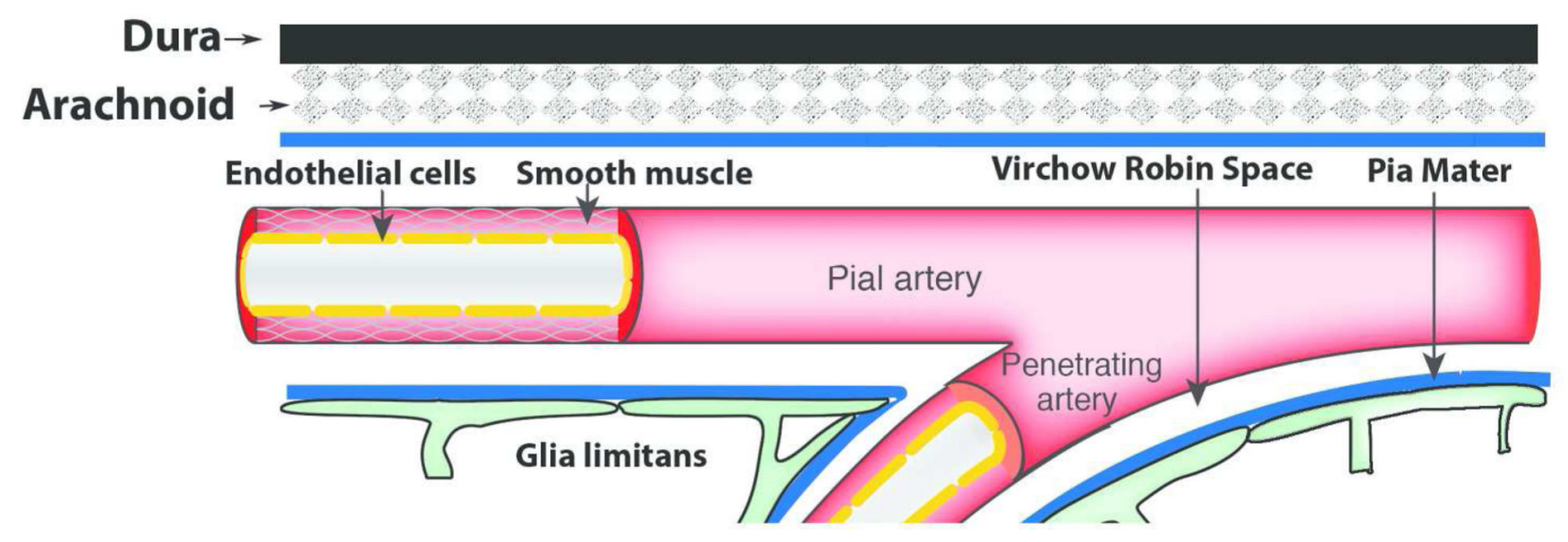

Figure 1.

Schematic drawings of the anatomy described by Quincke pertaining to the organization of the dura mater, arachnoid, and pia mater at the level of the skull (A) and spinal cord (B). Quincke described that a subdural space only exists in the brain (described as a "capillary fluid layer', A), whereas in the spinal cord no such space is present (B). 


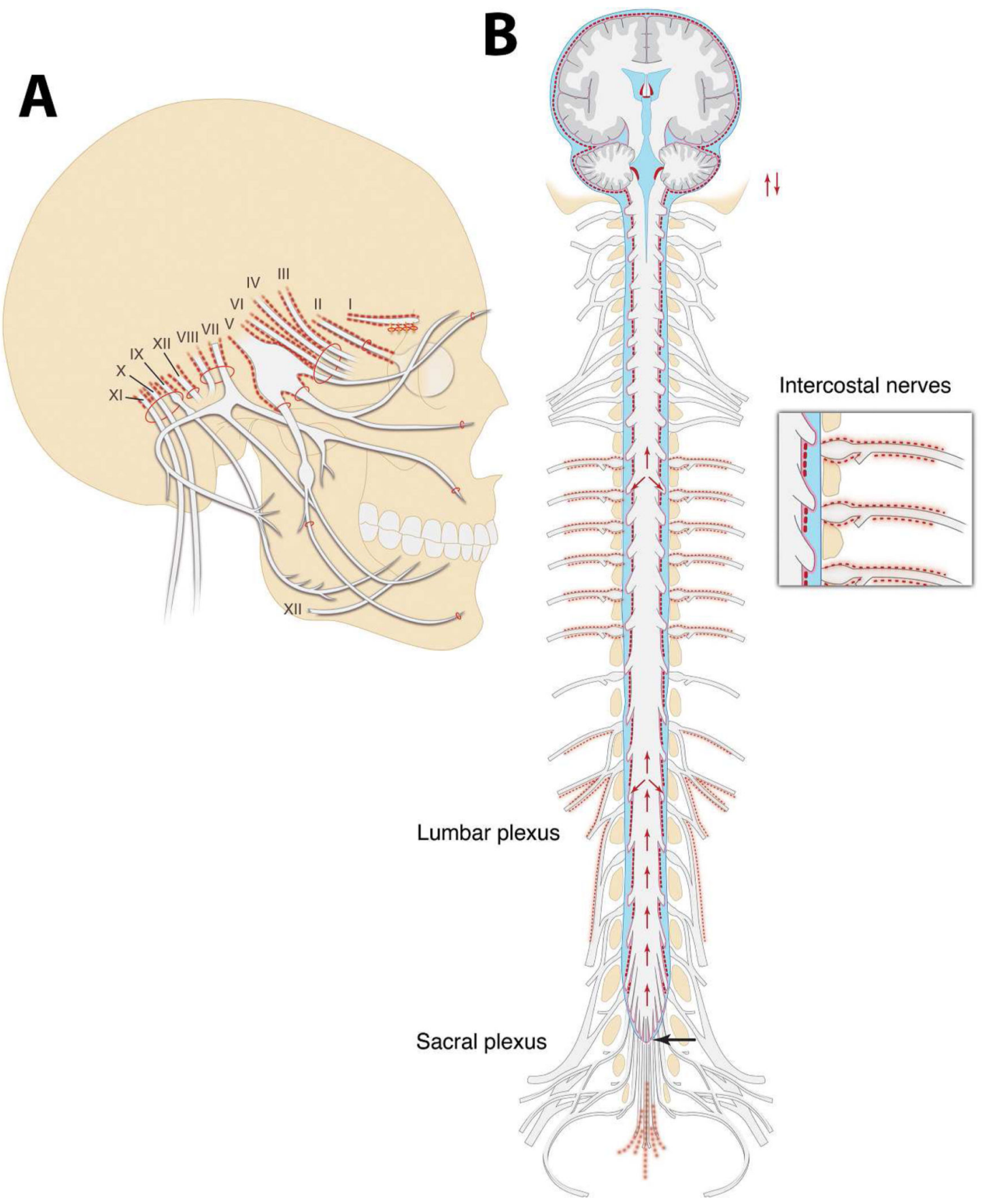

Figure 2.

Illustrations of where Quincke described the presence of cinnabar deposits along the cranial nerves (A), and spinal cord, nerve roots, peripheral nerves, and brain (B). The illustrations are based on a 'generic' humanoid skeleton although the actual experiments were done on dogs, cats, and rabbits. Quincke clearly articulated that the cinnabar was never observed within the brain or peripheral nerve parenchyma. However, he observed cinnabar on the surface of the brain and spinal cord, along intercostal nerves, along lumbar and sacral nerves 
(B), and always along the optic nerve all the way to "close to the entrance of the optic nerve into the eye" (A). 
A

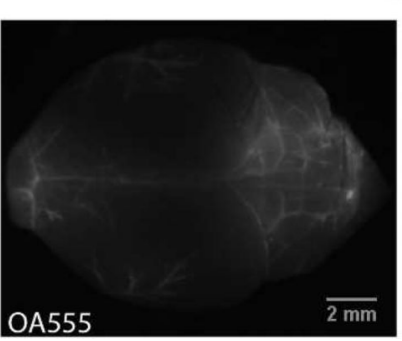

Brain

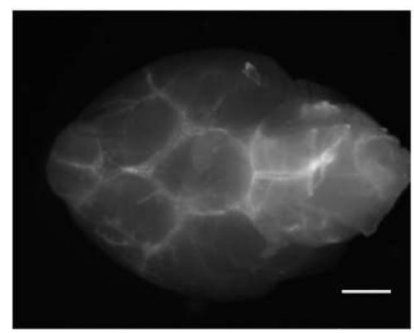

$\mathrm{BF}$

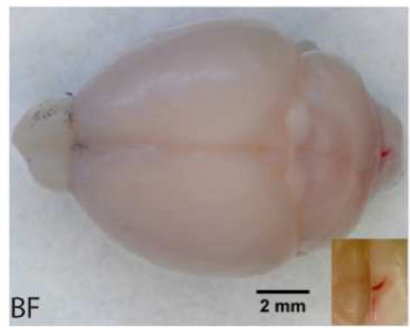

B

\section{$10 \%$ Cinnabar + 1\%OA555 Injections}

C
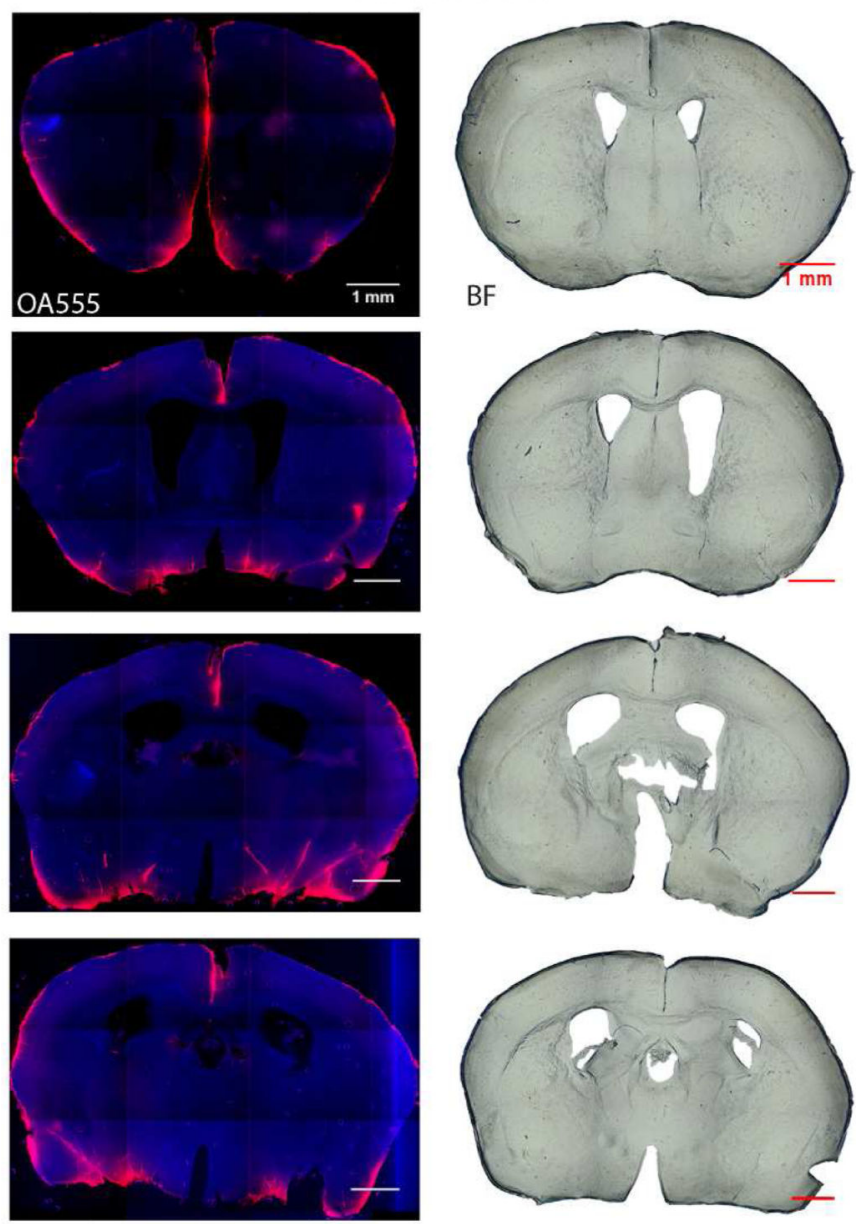

\section{Figure 3.}

Comparison of ovalbumin-Texas Red (OA555, 1\% in aCSF) and cinnabar (10\% in aCSF) CSF transport in adult male mice. (A) Fluorescence microscopy of OA555 (left panels) and brightfield (BF) microscopy of cinnabar (right panels) showing the distribution of the two tracers $30 \mathrm{~min}$ after injection into the cisterna magna. The brain is visualized from the top and the bottom. (B) Comparison of OA555 and cinnabar distribution in two spinal cord whole-mounts. Two spinal cords displaying the distribution of OA555 are shown in the middle whereas cinnabar is shown on either side, with high-power images of a few cinnabar crystals. (C) Coronal brain sections showing the distribution of OA555 (left panels are counterstained with DAPI) and cinnabar (right panels). Cinnabar did not enter the brain in any of the 7 mice analyzed and the BF images are negative for cinnabar. Scale bars $=2 \mathrm{~mm}$ (A), $4 \mathrm{~mm}$ (B), and $1 \mathrm{~mm}(\mathrm{C})$. 